\title{
The effect of process parameters on the material position of dissimilar friction stir welded AA2024-T3/5754-H22 joints
}

\author{
M. Gülbudak ${ }^{1}$, Y. Bozkurt ${ }^{2 *}$ \\ ${ }^{1}$ Marmara University, Department of Materials Technology, Institute For Graduate Studies in Pure and Applied \\ Sciences, 34722 Goztepe Campus, Istanbul, Turkey \\ ${ }^{2}$ Marmara University, Technology Faculty, Department of Metallurgy and Materials Engineering, 34722 Goztepe \\ Campus, Istanbul, Turkey
}

Received 3 November 2015, received in revised form 14 February 2016, accepted 3 March 2016

\begin{abstract}
In this study, the effect of process parameters on the material position, microstructural and mechanical properties such as microhardness distribution, ultimate tensile strength and optical microscope of the friction stir welded dissimilar joints was studied. The effects of the material positioning, the tool rotational speed and tool traverse speed as well as tool tilt angle on the joint strength were investigated. The experimental results showed that the positioning of the sheets played an important role in the strength of the joints. The joint strength was higher when the AA2024 sheet was positioned on the retreating side of the joint. The optimum test condition was obtained at a tool rotational speed of $900 \mathrm{rpm}$ and a tool traverse speed of $45 \mathrm{~mm} \mathrm{~min}^{-1}$. The microhardness in the advancing side of the heat affected zone/base metal interface zone of AA5754-H22 was found to be minimum, where the welded joints failed during the tensile studies.
\end{abstract}

Key words: friction stir welding, dissimilar weld, microhardness, mechanical properties

\section{Introduction}

There is an increasing need to design lightweight structures such as those in aircraft panels and vehicle body shells. Advanced joining technology is an integral part of the manufacturing processes of lightweight structures. Considerable effort has been expended to develop various joining processes and assess their suitability for use in lightweight structures [1]. The demand for producing joints of dissimilar materials which can provide appropriate mechanical properties and good cost reduction is continuously increasing due to their advantages [2].

These include not only technical advantages, such as desired product properties but also benefits in terms of production economics. Therefore, the existence of suitable joining techniques for dissimilar materials is indispensable. However, dissimilar metals are difficult to be joined with conventional fusion welding methods due to their different chemical and physical characteristics. Thus, solid state joining methods have received much attention in recent years. The conventional fusion welding of aluminum and its alloys has always been a great challenge for designers and technologists [3]. Unfortunately, the use of certain $\mathrm{Al}$ alloys is difficult because of their low weldability using conventional fusion welding techniques such as Metal Inert Gas (MIG) and Tungsten Inert Gas (TIG). The fusion welding of $\mathrm{Al}$ alloys is difficult due to the formation of welding defects such as blowholes and welding deformation as a result of the high coefficient of thermal expansion [4]. The main difficulty for dissimilar fusion welding is the severe reaction to form intermetallic compounds. These problems are not encountered in friction stir welding (FSW) because it is a solid-state process where the maximum process temperature does not reach the melting point of the welded materials [3].

FSW process, a special tool mounted on a rotating probe travels down through the length of the metal base plates in face-to-face contact; the interference between the welding tool and the metal to be welded gen-

*Corresponding author: e-mail address: ybozkurt@marmara.edu.tr 
Table 1. The chemical composition and mechanical properties of the aluminum sheets

\begin{tabular}{|c|c|c|c|c|c|c|c|c|c|c|c|}
\hline \multirow{2}{*}{ Materials } & \multicolumn{2}{|c|}{ Mechanical properties } & \multicolumn{9}{|c|}{ Chemical composition (wt.\%) } \\
\hline & $\begin{array}{l}\text { Tensile strength } \\
\qquad(\mathrm{MPa})\end{array}$ & $\begin{array}{c}\text { Elongation } \\
(\%)\end{array}$ & $\mathrm{Al}$ & $\mathrm{Si}$ & $\mathrm{Fe}$ & $\mathrm{Cu}$ & Mn & $\mathrm{Mg}$ & $\mathrm{Zn}$ & $\mathrm{Ti}$ & $\mathrm{Cr}$ \\
\hline AA2024-T3 & 435 & 17 & 93.11 & 0.07 & 0.14 & 4.5 & 0.65 & 1.5 & 0.01 & 0.02 & - \\
\hline AA $5754-\mathrm{H} 22$ & 245 & 14 & 95.29 & 0.25 & 0.31 & 0.02 & 0.38 & 3.2 & 0.18 & 0.12 & 0.23 \\
\hline
\end{tabular}

erates the plastically deformed zone through the associated stirring action. At the same time, the thermomechanical plasticized zone is produced by friction between the tool shoulder and the top plate surface and by contact of the neighboring material with the tool edges, inducing plastic deformation. However, no melting takes place in the weld zone during FSW. As a result, the joint is produced in a solid state [5]. It is important to note that for FSW of dissimilar materials, additional parameters, such as material arrangement and position of tool plunge with respect to the weld centerline, need to be considered, as well as general parameters such as tool geometry, tool rotation speed, and transverse tool speed. Because material flows and thermal hysteresis differ between the advancing and retreating sides, so material arrangement and tool plunge position exert a significant effect on weld formation [6]. Recently, some reports have been available on the FSW of dissimilar alloys, such as joining of 6063 to A319 [7], 6061-T6 to 5086-O [8], 2017-T6 to $6005 \mathrm{~A}-\mathrm{T} 6$ [9], 2024-T3 to 7075-T6 [10, 11], 2024-T351 to 2524-T351 aluminum alloys [12], Al to $\mathrm{Cu}$ [13], and AA6082 to AA2024 [14].

However, a study on dissimilar FSW joining of AA2024-T3/5754-H22 has not been reported so far to correlate the process parameters on the material position as known by the author except the AA2024-0 to AA5754-H22 dissimilar aluminum alloys [15]. This study was focused on the different welding parameters and limited microstructural observations. Here, we discuss the influence of distinct weld parameters including the tool tilt angle on the joint efficiency and microstructure formation. The microand macrostructure, microhardness profile and tensile properties of the welds were examined. The objective of the present study was to clarify how the welding parameters are related to the material position on mechanical properties of AA2024-T3 and AA5754-H22 aluminum alloys.

\section{Experimental procedure}

In this study, dissimilar FSW joints are produced from aluminum alloys AA2024-T3 and AA5754-H22 with sheet dimensions that are nominally $150 \times 50 \times 2$ $\mathrm{mm}^{3}$. The chemical compositions and mechanical
Table 2. Material combination of FSWed sheets

\begin{tabular}{lcc}
\hline \multicolumn{2}{c}{ Materials } & Combination \\
\cline { 1 - 2 } Advancing side & Retreating side & \\
\hline AA5754-H22 & AA2024-T3 & Case I \\
AA2024-T3 & AA5754-H22 & Case II \\
\hline
\end{tabular}

properties of these $\mathrm{Al}$ alloy sheets are given in Table 1.

AA2024-T3 and AA5754-H22 sheets were successfully butt joined by FSW with different tool rotation speeds (900, 1500 and $2100 \mathrm{rpm}$ ) and traverse speeds (45, 75 and $\left.115 \mathrm{~mm} \mathrm{~min}^{-1}\right)$ with different tool tilt angle $\left(1^{\circ}, 2^{\circ}\right.$ and $\left.3^{\circ}\right)$ which were chosen according to the optimum results [16]. AA2024-T3 and AA5754-H22 alloys were respectively kept on the advancing side (AS) and retreating side (RS) of the joint line. Two case test specimens were produced regarding the position of $\mathrm{Al}$ sheets as shown in Table 2. In the first case, indicated as Case I, the position AA2024-T3 sheet was placed $\mathrm{RS}$ of the FSW. In the second case indicated as Case II, the position of the AA2024-T3 sheet was placed AS of the FSW. In the remaining section of the article, these two conditions are notified as Case I and Case II condition, respectively.

This plate positioning was chosen based on the consideration that the microstructure and the mechanical properties of the stirred zone are influenced by the AS and RS of the joint in order to obtain defect-free joints. Such dependence of the strength on the material position was previously observed for dissimilar AA6082/AA2024 [13], Al 6013/Mg AZ31 [17], AA5083-H111/AA6351-T6 [18], AA2024/AA7075 [10]. All the FSW experiments were conducted with an FSW adapted numerically controlled, universal milling machine as shown in Fig. 1 for Case II condition. FSW steps are shown in Figs. $1 \mathrm{a}-\mathrm{d}$.

The FSW tool was made of high-speed steel coated with Aluminum Titanium Nitride (AlTiN) and had a hardness of 60 HRC. This tool is shown in Fig. 2. In Figs. 2a,b are shown the schematic view, and image of the AlTiN coated FSW tool, respectively.

Microstructural characterization was performed using an optical microscope (OM). The welded sam- 

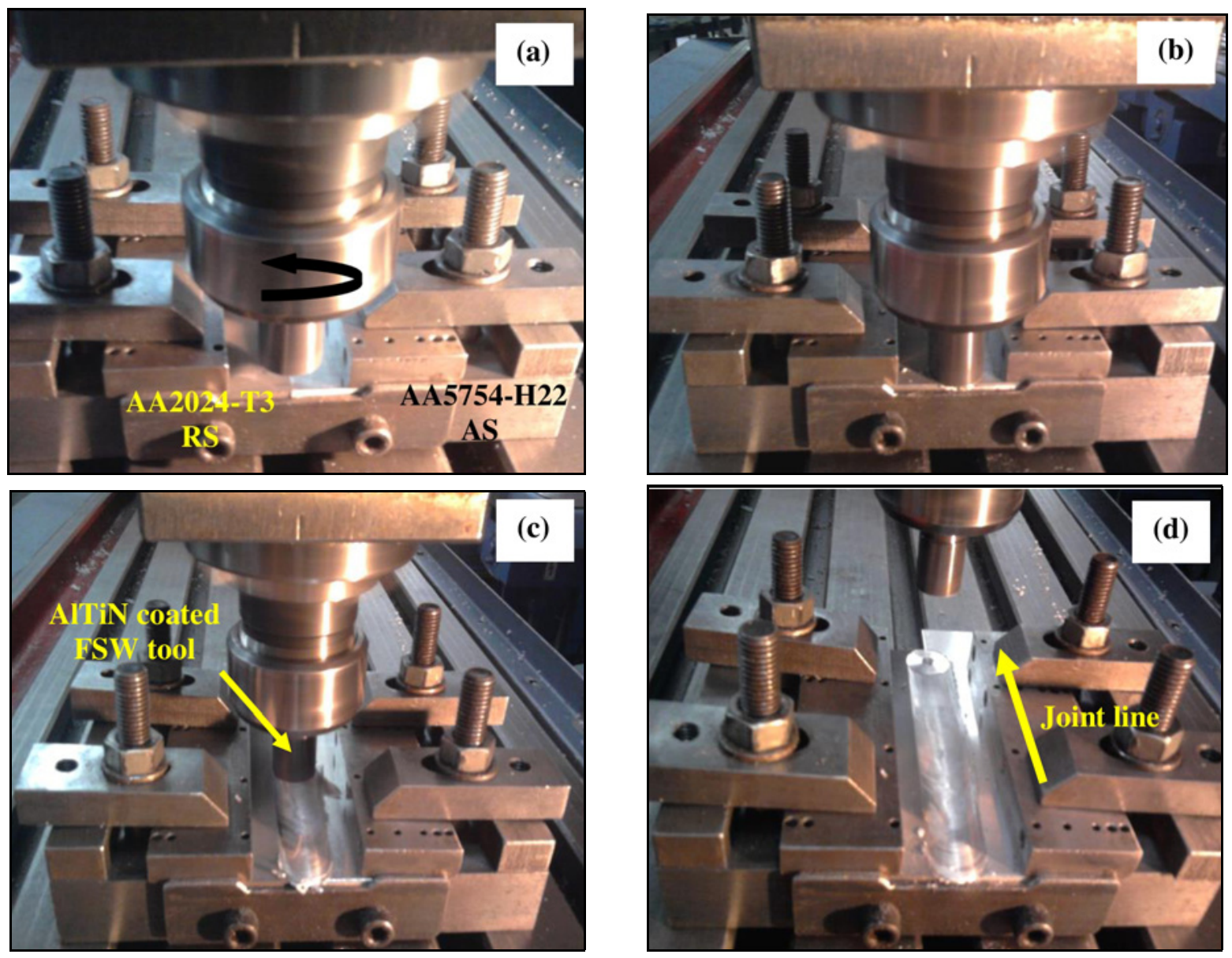

Fig. 1. Friction stir welding process for Case II condition: a) rotating tool prior to penetration into the butt joint; b) tool shoulder makes contact with the part, creating heat; c) restricting further penetration while expanding the hot zone and part moves under the tool, creating a friction stir weld nugget; d) retraction the tool from joining zone [3].

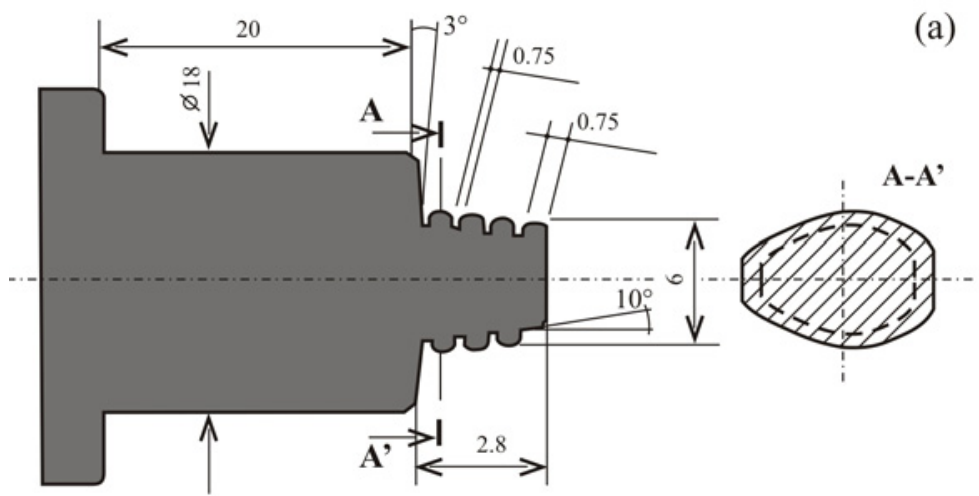

(a)

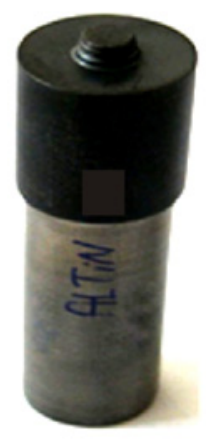

(b)

Fig. 2. a) schematic view; b) image of the AlTiN coated FSW tool.

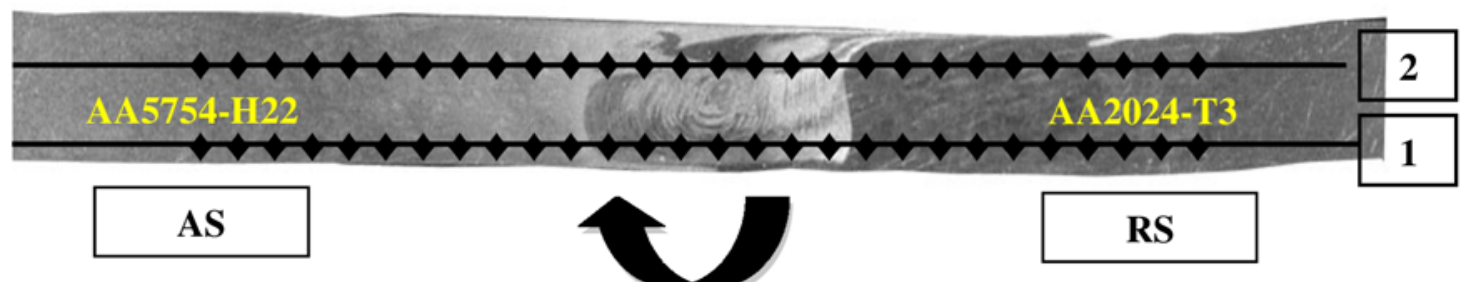

Fig. 3. The cross-sectional view of microhardness measurements for Case I condition: 1: lower zone; 2: upper zone. 


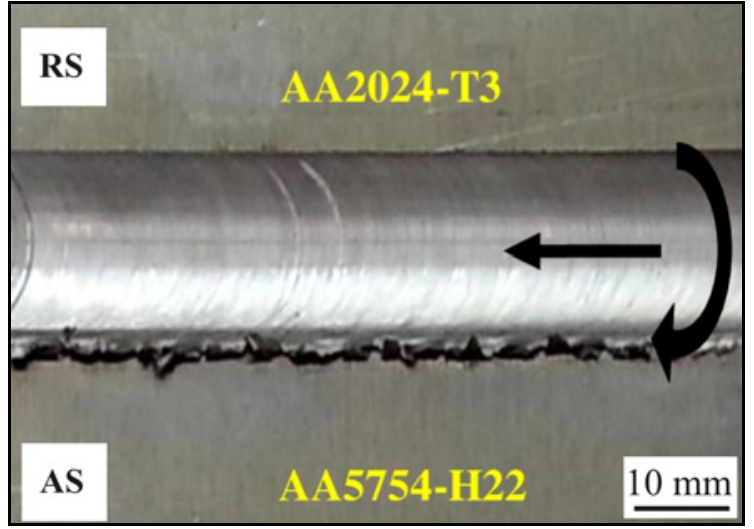

Fig. 4. The surface appearance of the FSW of AA2024-T3 and AA5754-H22 aluminum alloy plates for Case I condition.

ples for $\mathrm{OM}$ were transversely sectioned and polished using the conventional mechanical polishing method. Micro-etching was carried out using Keller's reagent at ambient temperature to reveal the grain structures of the welds. The Vickers microhardness was also measured across the center of each joint with $200 \mathrm{gf}$ loading and dwell time of $15 \mathrm{~s}$ at intervals of about $1 \mathrm{~mm}$ from number 1 and 2 line for Case I and Case II condition. In Fig. 3, the cross-sectional view of microhardness measurements for Case I condition is shown.

The tensile specimens were prepared as per ASTM E8M-09 standard [19] using Zwick/Z010 universal type tensile test machine to determine the tensile properties of the joints. At least three specimens were tested under the same conditions to guarantee the reliability of the results.

\section{Results and discussion}

\subsection{Microstructural aspects}

Figure 4 shows the surface appearance of the FSW of AA2024-T3 and AA5754-H22 aluminum alloy plates for Case I condition for the side in contact with the shoulder tool (top view). It can be seen that the sound weld without obvious defects such as cracks or tunnel type defects originated when tool rotation speed was $900 \mathrm{rpm}$, and traverse speed was $45 \mathrm{~mm} \mathrm{~min}^{-1}$ with the tool moving along the center. This surface was characterized by the so-called 'wake effect' [20] with the presence of semicircular features, similar to those induced by a conventional milling process.

The microstructure of selected FSW joints is presented in Figs. 5-9. Macroscopic views of the crosssection of the joints manufactured at a tool rotation speed of $900 \mathrm{rpm}$ and traverse speeds of $45 \mathrm{~mm} \mathrm{~min}^{-1}$

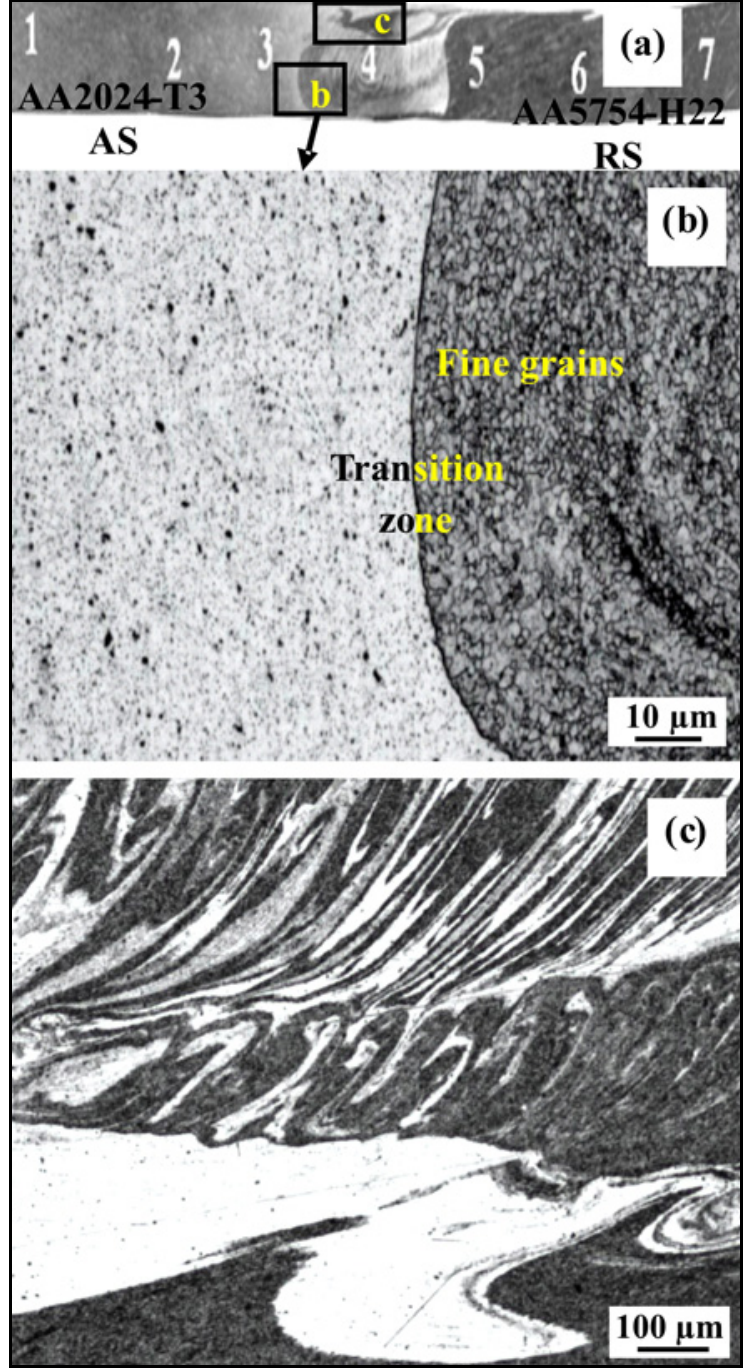

Fig. 5. Macrographs of the dissimilar FSWed joints at 900/45/2 welding parameters for Case II condition: a) macroscopic cross-section; b) transition zone; c) the top side of transition/DXZ zone.

and $1^{\circ}$ and $2^{\circ}$ tool tilt angle (900/45/1 and 900/45/2) are shown in Figs. 5a and 8a, respectively.

The base metals of AA2024-T3 and AA5754-H22 $\mathrm{Al}$ alloys are shown on the AS in Fig. 6 (1) and on the RS in Fig. 7 (7), respectively. The microstructure of the FSW joint is formally divided into four different zones [3, 10, 21], as shown in Figs. 5a and 8a. In Fig 5a: (2) the AS of HAZ; (3) the AS of TMAZ; (6) the RS of HAZ; (5) the RS of TMAZ; and (4) the weld nugget (stir zone). It can be seen that sound defect-free joints were obtained in the dissimilar AA2024/5754 Al alloys. The microstructure of transition zone between AA2024/5754 stir zone (SZ) of trail run is presented in Fig. 5b. The dynamically recrystallized zone (DXZ) is the stirred zone, where the material has undergone severe plastic deformation resulting in fine equiaxed grains in the top side of transition/DXZ zone as shown in Fig. 5c [22]. 

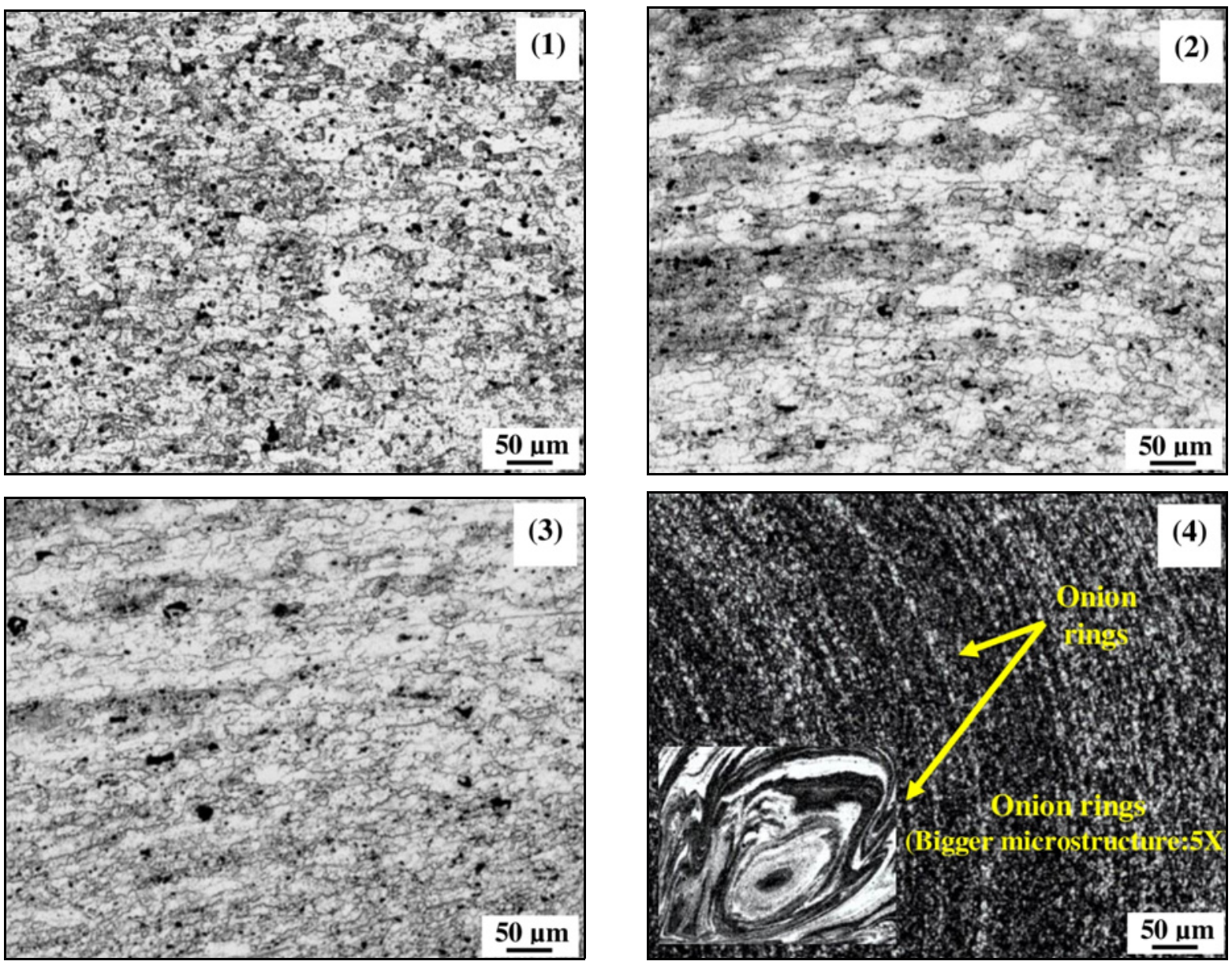

Fig. 6. Microstructural views of the dissimilar FSWed joints at 900/45/2 welding parameters (1-4 zone in Fig 4): 1) the base metal of AA2024-T3; 2) the AS of HAZ zone; 3) the AS of TMAZ zone, and 4) the weld nugget (stir zone).

The microstructure of the different regions of the FSWed dissimilar $\mathrm{Al}$ alloys is also shown in Figs. 6 and $7(1-7)$. Compared with the base metal, the grain structure in the AS and RS of the HAZ zone shows no distinct difference excluding the dark degree of the grain boundaries in Fig. 6 (1-2) and Fig. 7 (6-7) [23]. However, there is no plastic deformation occurring in these areas. In the AS and RS, the TMAZ zone exhibits highly elongated and rotated grains without recrystallization, which are affected by thermal and drastic plastic deformation of SZ during FSW as shown in Fig. 6 (3) and Fig. 7 (5) [23, 24]. In SZ Fig. 6 (4), the microstructure is characterized by dynamically recrystallized fine equiaxed grains owing to the drastic plastic deformation which results in the rearrangement of the grains exposure to the high stress and heat produced by stirring tool during FSW. It is interesting to note that the onion rings are clearly visible in the stir zones which are typically formed by the process of frictional heat due to rotation of the tool where the forward movement extrudes metal from the AS to RS of the tool [3]. The existence of onion rings in the SZ is a direct evidence of characteristic material transport phenomena occurring during FSW. Other authors have reported a similar behavior and related it to a partial recrystallization in the stirred zone and onion rings [25-27].

There is an evident boundary between AA5754/ 2024 stir zone (transition zone) in Fig. 8b. The stir zone is showed between AA5754/2024 interface in Fig. 8c. The formation of the onion rings is due to the process of a friction heating due to the rotation of the tool and the forward movement extruding the material around the retreating side of the tool, as described by Krishnan [28]. The plasticized dissimilar alloys are mechanically joined to each other in this zone. Some degree of penetration of AA5754 to 2024 or reverse takes place as shown in Figs. 8c and 9 (3). What appears to be band type is noticeable in the $\mathrm{SZ}$ from the AS to the SZ and the band geometry is different for different tool traverse speed as shown in Fig. 9 (3) [27].

The coarser grain structure of BM changes to a finer grain structure after FSW. In the HAZ (Fig. 9 (1) and (5)), between TMAZ and BM regions both at the AS and RS, there were no noticeable changes in 

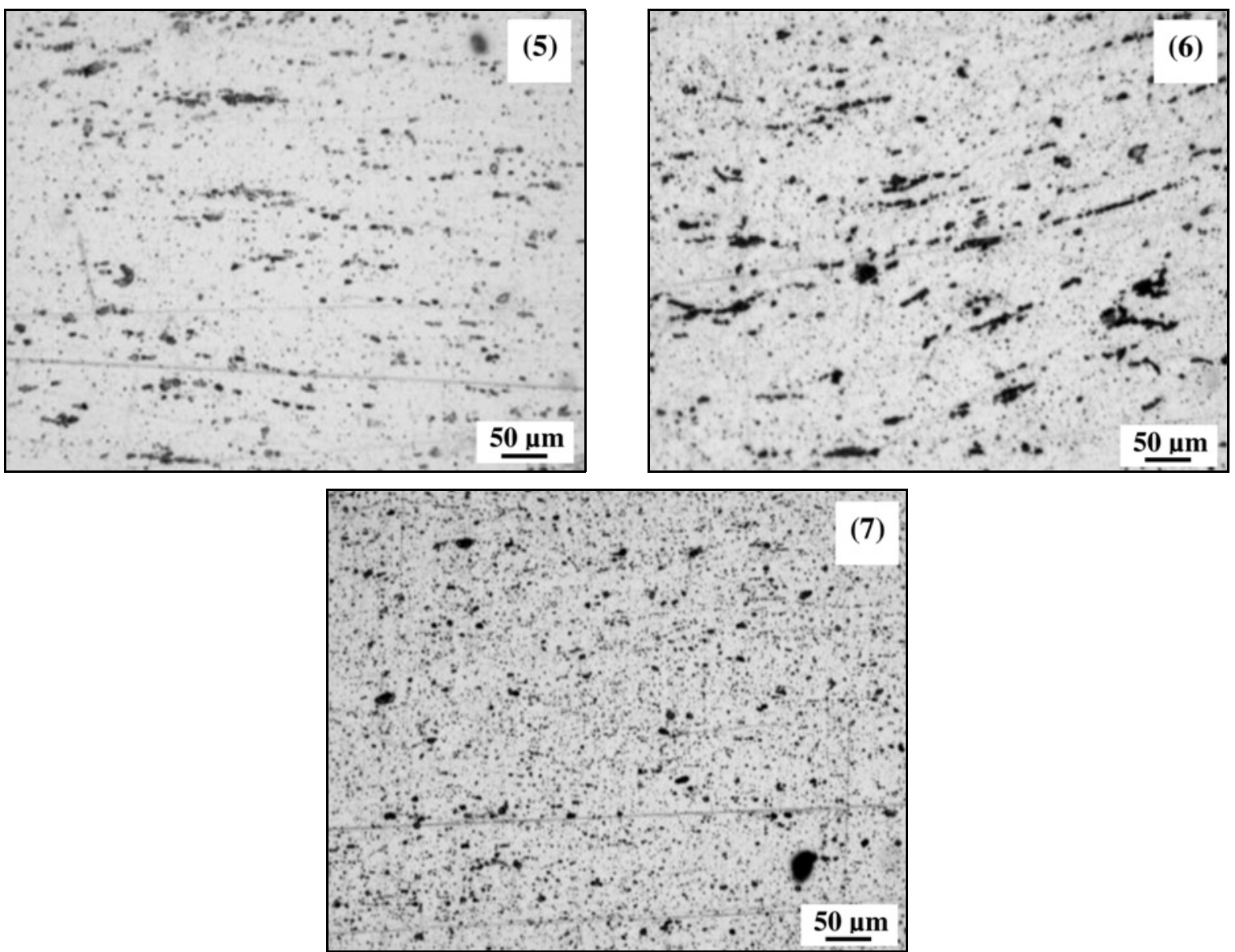

Fig. 7. Microstructural views of the dissimilar FSWed joints at 900/45/2 welding parameters (5-7 zone in Fig. 4): 5) the RS of TMAZ zone; 6) the RS of HAZ, and 7) the base metal of AA5754-H22.

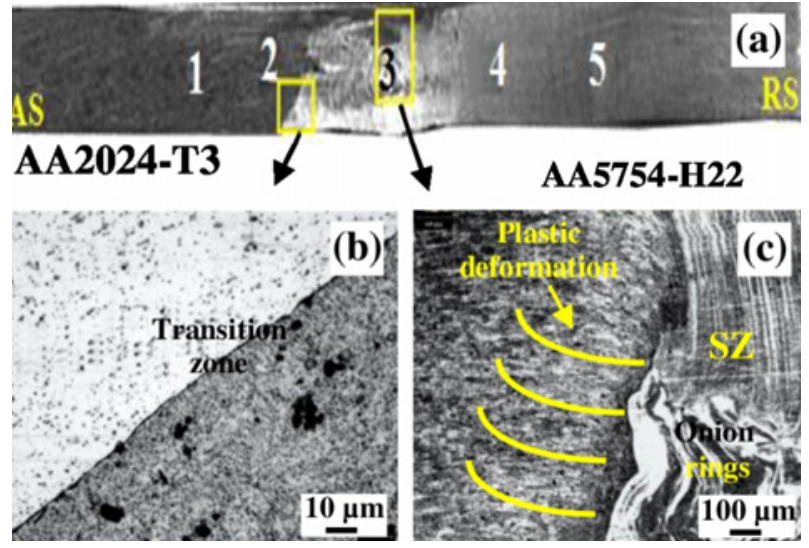

Fig. 8. Macrographs of the dissimilar FSWed joints at 900/45/1 welding parameters for Case I condition; a) macroscopic cross-section; b) transition zone; c) the stir zone of AA5754/AA2024 interface zone.

the grain structure compared to the respective unaffected base materials [3, 29]. Mahabunphachai et al. [30] analyzed that the changes of the grain size in the microstructure analysis due to the effects of el- evated temperatures and strain rates were not significant; therefore, it was concluded that the decrease in the flow stress at high-temperature levels was mainly due to the thermally activated dislocation lines. The reason that the decrease of flow stress at high temperature was caused by dislocations because of the heat input during joining of dissimilar alloys resulting in a dissolution and/or coarsening of strengthening precipitates. Comparison of the both sides of TMAZ shows a discernible increase in the grain size due to the dynamic recrystallization (Fig. 9 (2 and 4)), and this may affect the tensile properties. When the heat input was higher, dynamic recrystallization comprised under the severe thermomechanical effect in the TMAZ, representing equiaxed recrystallized grains. As the heat input was increased, the recrystallized grains in the TMAZ increased in size and were comparable to those in the SZ and HAZ.

\subsection{Tensile testing}

The tensile test results of the dissimilar FSWed joints produced with different welding parameters for Case I and Case II are shown in Fig. 10. Consistent 

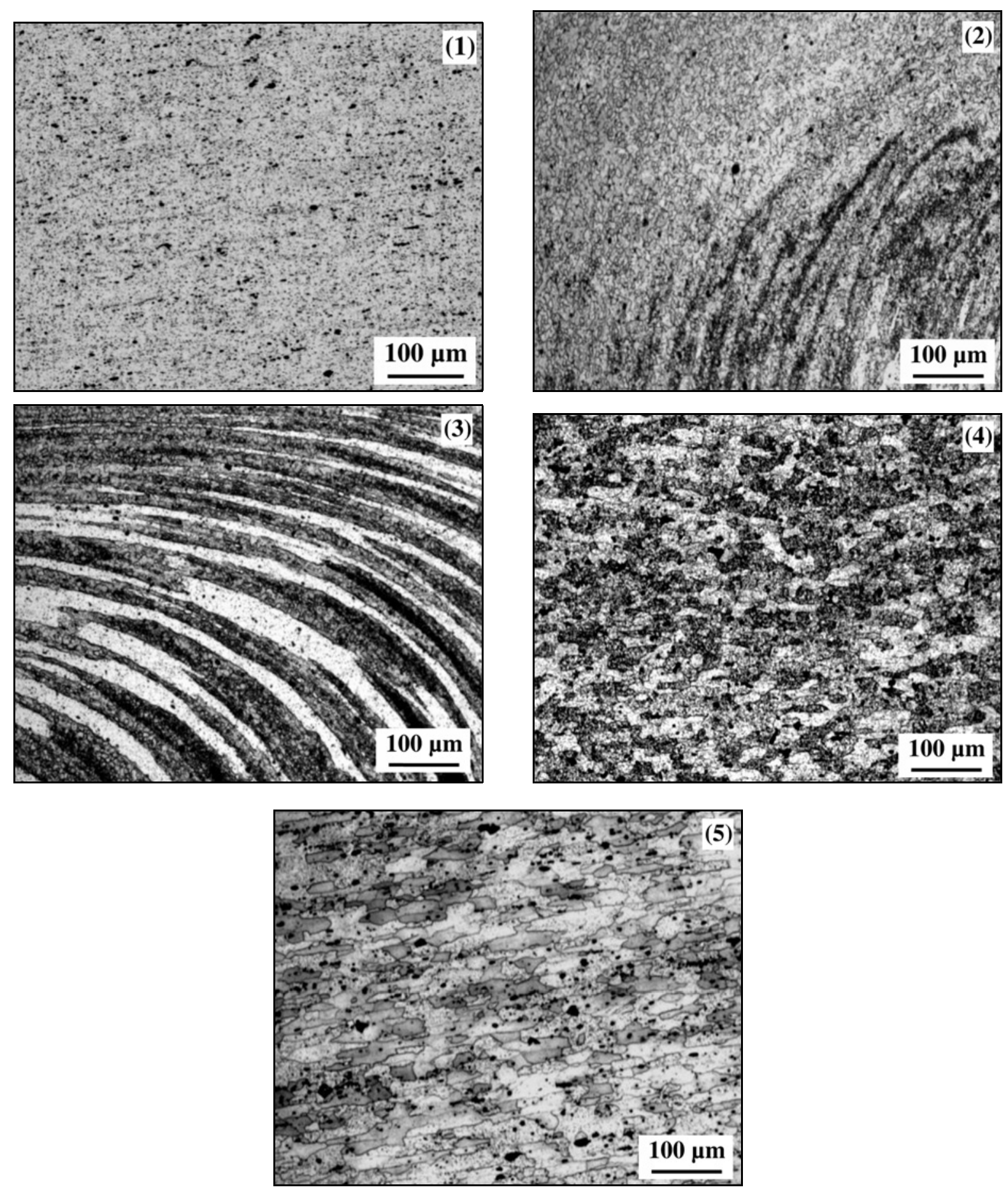

Fig. 9. Microstructural views of the dissimilar FSWed joints at 900/45/2 welding parameters (1-5 zone in Fig. 8 ): 1. the AS of HAZ zone; 2. the AS of TMAZ zone; 3. the weld nugget (stir zone); 4. the RS of TMAZ zone, and 5 . the RS of HAZ.

and repetitive results were obtained from the tensile tests. Various microstructural features contain grain structure advancement, its texture, temperature distribution, recrystallization processes and precipitation of intermetallic components. These factors influence the UTS and the quality of the FSW [31]. Maximum UTS of $235 \mathrm{MPa}$ and minimum $140 \mathrm{MPa}$ were obtained for Case I and Case II condition, respectively. These results clearly can be seen in Fig. 10a marked red. When 2024Al alloy was located on the $\mathrm{RS}$, the tensile strength increased [10]. The maximum joint efficiency value was obtained $96 \%$ (that is $\mathrm{UTS}_{\mathrm{FSW}}$ /UTS base material $\left.\times 100\right)$ which was very slightly lower than the tensile strength of AA5754-H22 

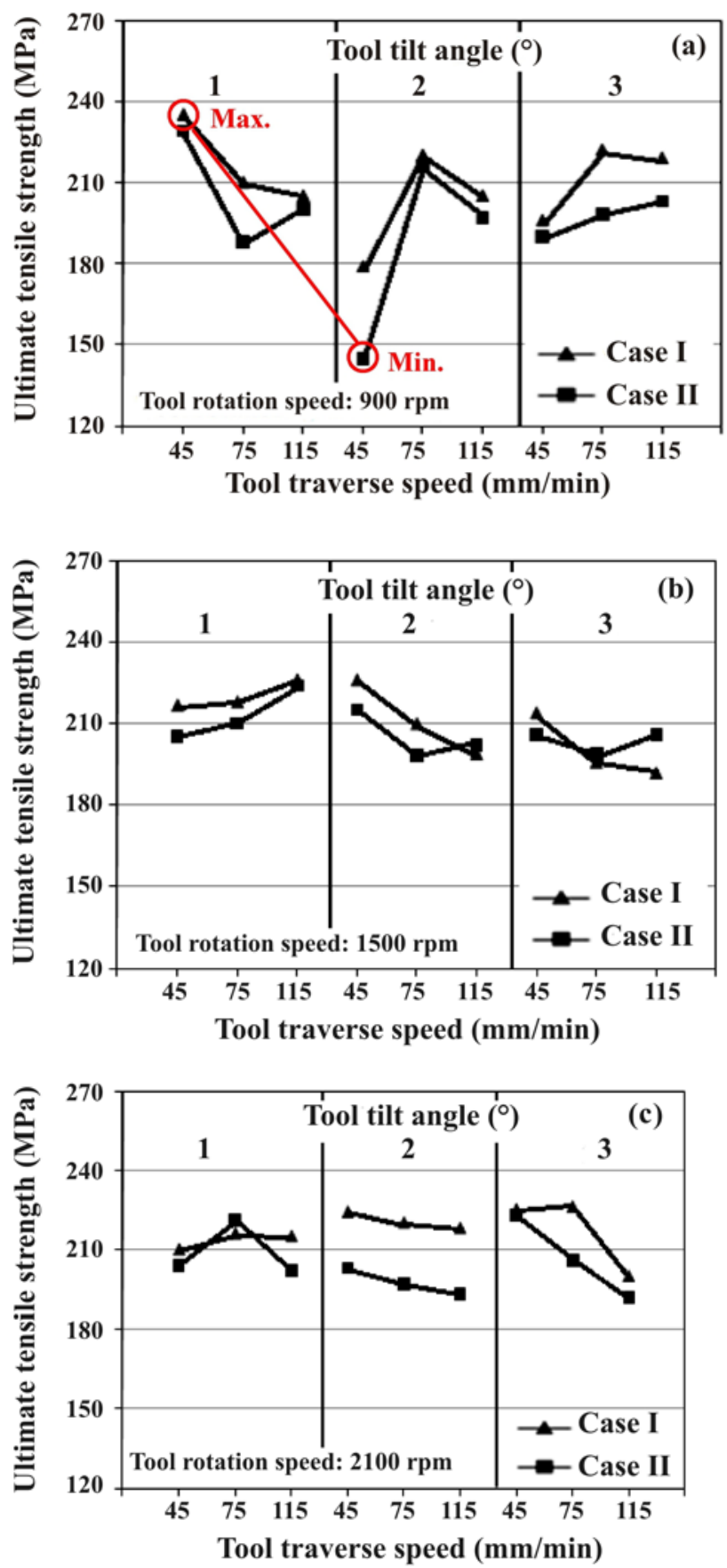

Fig. 10. Tensile test results of the dissimilar FSWed joints for Case I and Case II condition.

BM, but much lower than AA2024-T3 BM (54 \%). The tool tilt angle and the materials position had a strong effect on the tensile properties. The tensile strength of FSW joints mainly increases due to the plastic deformation and grain orientation (Fig. 8c). Due to the higher degree of grain refinement in the SZ during tool spinning, the tensile strength increase in the SZ is higher than in the BM. However, the grains of the SZ were refined by tool spinning, and the grains in the SZ of the FSW joint underwent the grain refinement processes due to the tool rotation and traverse [32].

In general, increasing tool rotation speed causes the peak temperature in the sheet being FSWed to rise. The degree of annealing and consequently thermal stress relieving is more at higher peak temperature for materials volume on the RS in the SZ of the tool. This results in a decrease in residual stress. It can be seen that the UTS value for $2^{\circ}$ and $3^{\circ}$ tool tilt angle decreases with increasing the tool traverse speed and tool rotation speed (Figs. 10b,c) for both Case I and Case II condition in the tool rotation speed at 1500 and $2100 \mathrm{rpm}$, as was also indicated by Mishra et al. [33]. However, as seen in Figs. 10a and 10c, the UTS values also decreased in $1^{\circ}$ tool tilt angle at 900 $\mathrm{rpm}$ for both conditions and at $2100 \mathrm{rpm}$ tool rotation speed for Case II condition, respectively. On the contrary, it increased for both conditions at $900 \mathrm{rpm}$ for $2^{\circ}$ and $3^{\circ}$, and at $1500 \mathrm{rpm}$ for $1^{\circ}$ tool rotation speed and tool tilt angle, respectively (Figs. 10a,b). Only for Case I condition the UTS value was increased at $2100 \mathrm{rpm}$ tool rotation speed and $1^{\circ}$ tool tilt angle. Major torque, load, and temperature represent that the material is heated up to a wider field and stirred efficiently to fill the cavities unfilled at low tool tilt angle. The increase of tool tilt angle also results in an increase of the forging force of the tool and heat input, generating flash around the weld zone and consequently reducing the volume of material under the tool shoulder. Finally, more cavities in the weld zone are formed.

The fracture surfaces of the joints produced by Case I and Case II condition after the tensile testing are shown in Fig. 11. The specimens extracted from the FSW joints produced by Case I (Fig. 11a) and Case II (Fig. 11b) condition fractured between boundary region $\mathrm{AS}$ of the $\mathrm{HAZ} / \mathrm{BM}$ and $\mathrm{RS}$ of the SZ/TMAZ, respectively. During tensile testing, most of the FSW joints were fractured on the AA5754-H22 side as shown in Figs. 11a,b. A preferential fracture was also detected by Larsson et al. [34], however, they initially proposed that the softer material should be placed on the advancing side of the weld to produce better welds, and many researchers have subsequently reported similar results $[10,13]$. On the other hand, some researchers reported that superior welds were obtained when the harder material was placed on the advancing side [35] or that the material arrangement did not affect the weld properties. In our study, the joint efficiency was affected by the material position. The max. tensile properties were obtained for the FSW joints with the high strength Al alloy (AA2024-T3) positioned on RS of the FSW using the $900 / 45 / 1$ welding parameters. Such dependence of the strength on the material position was previously observed in $[3$, $13,36]$. 


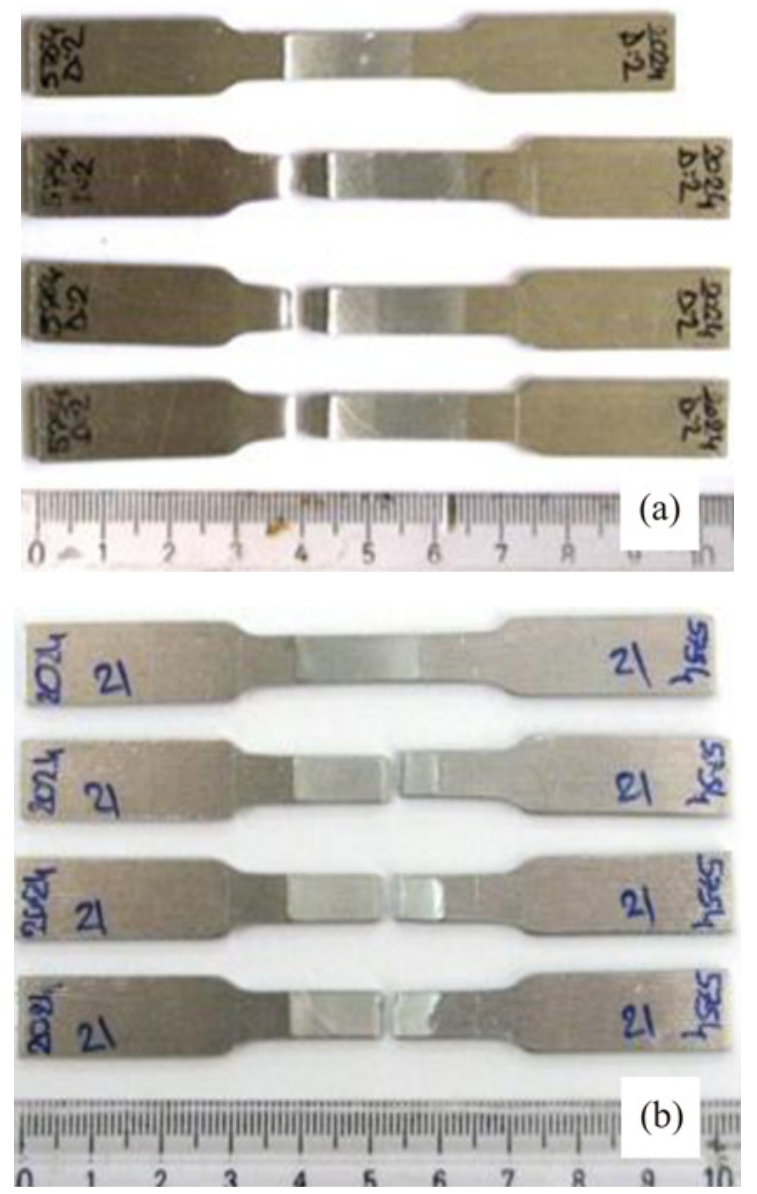

Fig. 11. Fracture appearances after tensile tests: a) Case I, b) Case II.

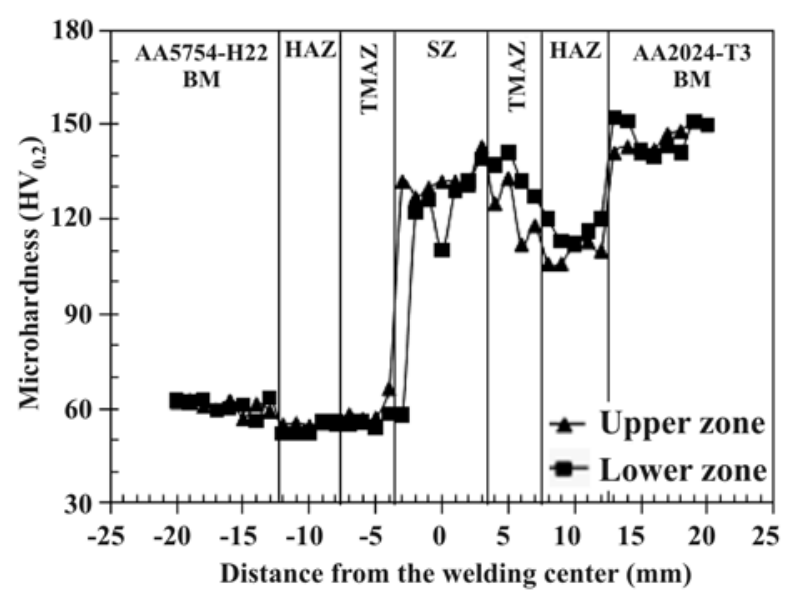

Fig. 12. Microhardness profiles on the cross-section of the FSWed dissimilar joints at 900/45/1 welding parameters for Case I condition.

\subsection{Microhardness profiles}

Figures 12 and 13 show the microhardness profiles

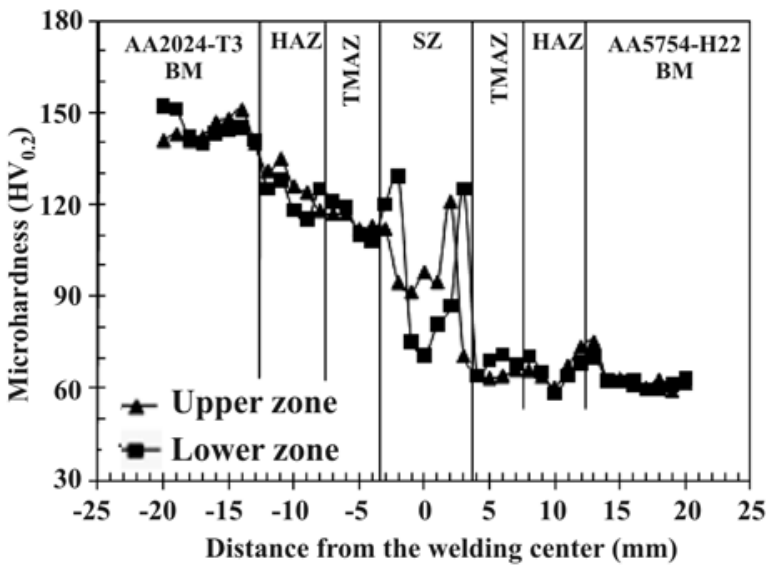

Fig. 13. Microhardness profiles on the cross-section of the FSWed dissimilar joints at 900/45/2 welding parameters for Case II condition.

on the cross-section of the FSWed dissimilar joints with 900/45/2 and 900/45/1 welding parameters for Case II and Case I condition, respectively. No significant differences were observed between the microhardness of the upper and lower zones. However, dissimilar weld profiles were composed of two half$\mathrm{W}$. This is due to the hardening precipitates evolution during welding. The transition between both sides occurs in the SZ, whose hardness depends on its composition [1]. The microhardness values of the BM were obtained in ranges of $60-68 \mathrm{HV}_{0.2}$ for AA5754 and $143-150 \mathrm{HV}_{0.2}$ for AA2024. For Case I condition, microhardness distribution in the $\mathrm{SZ}$ is increased from AS to RS. In this zone, microhardness changes in the range of $108-144 \mathrm{HV}_{0.2}$. Microhardness values are decreasing towards the SZ of both sides of TMAZ and HAZ zone. Aluminum alloys are classified into precipitation-hardenable alloys and solidsolution-hardenable alloys, and it was reported that the softening of the welds did not occur during FSW for the solid-solution-hardenable alloys [14]. In the SZ and near regions, the microhardness has a tendency to increase and reaches an equal value to that of BM again. The minimum points are located on AS side of the HAZ for Case I condition.

For Case II condition, in the SZ the microhardness changes in the range of $68-122 \mathrm{HV}_{0.2}$. From the $\mathrm{SZ}$ to AS of the HAZ zone, the microhardness is increased. The enhancement of tensile properties of the joints observed when AA2024-T3 was located on the AS was mainly due to the higher values of hardness in the HAZ [10]. Most of the precipitates dissolved both in TMAZ and SZ during welding with the peak temperature in the SZ. Therefore, the increase of temperature is sufficient for precipitates to be dissolved during FSW [37]. In the AS of TMAZ zone, the microhardness gradually decreases according to BM. But, in 
the RS of TMAZ and HAZ, the microhardness values are almost similar. This significantly influences the observed failure load and failure mechanism and thus, heat treatment post welding is required to ensure uniformity of properties [1]. It should be noted that a small increase in microhardness with respect to the TMAZ occurs in the DXZ (SZ) resulting from the fine grain size in the DXZ. These microhardness profiles suggest that ultimate failure should happen someplace between the RS of SZ/TMAZ zone for the AA2024/5754 alloy when statically loaded.

\section{Conclusions}

The following conclusions are obtained from this study:

1. In the microstructural investigation, no visible superficial porosity or macroscopic defects have been observed in dissimilar AA2024-T3/5754-H22 joints. Excellent bondage was achieved between both alloys.

2 . The max. tensile properties were obtained for these joints with the high strength $\mathrm{Al}$ alloys positioned on RS of the joint (Case I condition). Thus, the positioning of the sheets played an important role on the UTS of the joints.

3. Maximum UTS $235 \mathrm{MPa}$ and minimum $140 \mathrm{MPa}$ were obtained for Case I and Case II condition, respectively.

4. The specimens extracted from the FSW joints produced by Case I and Case II condition fractured between boundary region $\mathrm{AS}$ of the $\mathrm{HAZ} / \mathrm{BM}$ and $\mathrm{RS}$ of the SZ/TMAZ, respectively

5. The microhardness in the AS of HAZ/BM zone for Case I condition was found to be minimum, where the welded joints failed during the tensile studies.

6. For Case I condition, microhardness distribution in the SZ increased from AS to RS. For Case II condition, in the AS of TMAZ zone, the microhardness gradually decreased according to BM. But, in the RS of TMAZ and HAZ, the microhardness values are almost similar.

7. The mechanical and metallurgical characteristics have shown positive connection which is clearly apparent from results obtained for different tool tilt angle. Consequently, tool tilt angle is a very important welding parameter.

\section{Acknowledgement}

The authors are deeply grateful for the financial support of Marmara University Scientific Research Fund by Grant No: FEN-C-YLP-060911-0279.

\section{References}

[1] He, X., Gu, F., Ball, A.: Progress. Mat. Sci., 65, 2014, p. 1. doi:10.1016/j.pmatsci.2014.03.003

[2] Anawa, E. M., Olabi, A. G.: Optics Laser Technol., 40, 2008, p. 379. doi:10.1016/j.optlastec.2007.07.001

[3] Bozkurt, Y., Duman, S.: Scientific Research and Ess. 6, 2011, p. 3702 .

[4] Ferjutz, K., Davis, J. R., Wheaton, N. D.: ASM Handbook: Welding, Brazing, and Soldering. Volume 6 . Materials Park, ASM International 1993

[5] Bozkurt, Y.: Materiali in Tehnologije/Mat. Techn., 45, 2011, p. 407.

[6] Song, S. W., Kim, B. C., Yoon, T. J., Kim, N. K., Kim, I. B., Kang, C. Y.: Mat. Trans., 51, 2010, p. 1319. doi:10.2320/matertrans.M2010032

[7] Krishnan, M. M., Marimuthu, K.: Int. J. Mat. Res., 105, 2014, p. 507. doi:10.3139/146.111054

[8] Aval, H. J., Serajzadeh, S., Kokabi, A. H.: J. Mater. Sci., 46, 2011, p. 3258. doi:10.1007/s10853-010-5213-x

[9] Simar, A., Jonckheere, C., Deplus, K., Pardoen, T., De Meester, B.: Sci. Technol. Weld. Join., 15, 2010, p. 254. doi:10.1179/136217110X12665048207737

[10] Zadpoor, A. A., Sinke, J., Benedictus, R.: Metall. Mater. Trans. A, 41, 2010, p. 3365. doi:10.1007/s11661-010-0403-3

[11] Khodir, S. A., Shibayanagi, T.: Mat. Sci. Eng. B, 148, 2008, p. 82. doi:10.1016/j.mseb.2007.09.024

[12] Yang, B., Yan, J., Sutton, M. A., Reynolds, A. P.: Mater. Sci. Eng. A, 364, 2004, p. 55. doi:10.1016/S0921-5093(03)00532-X

[13] Sarsilmaz, F.: Mat. Test., 54, 2012, p. 85. doi: $10.3139 / 120.110300$

[14] Cavaliere, P., Santis, A. D., Panella, F., Squillace, A.: Mat. Des., 30, 2009, p. 609. doi:10.1016/i.matdes.2008.05.044

[15] Vural, M., Ogur, A., Cam, G., Ozarpa, C.: Arch. Mat. Sci. Eng., 28, 2007, p. 49.

[16] Gulbudak, M.: Friction Stir Welding Properties of Dissimilar Aluminium Plate Couple. Istanbul, Marmara University, Institute For Graduate Studies in Pure and Applied Sciences 2013.

[17] Zhao, Y., Lu, Z., Yan, K., Huang, L.: Mat. Des., 65, 2015, p. 675. doi:10.1016/j.matdes.2014.09.046

[18] Palanivel, R., Mathews, P. K., Dinaharan, I., Murugan, N.: Trans. Nonferr. Met. Soc. China, 24, 2014, p. 58. doi:10.1016/S1003-6326(14)63028-4

[19] ASTM E8/E8M-09. Standard Test Methods for Tension Testing of Metallic Materials. Materials Park, ASTM International 2009.

[20] Bozkurt, Y., Uzun, H., Salman, S.: J. Comp. Mater., 45, 2011, p. 2237. doi:10.1177/0021998311401067

[21] Zhou, C., Yang, X., Luan, G.: Mat Chem Phys., 98, 2006, p. 285. doi:10.1016/j.matchemphys.2005.09.019

[22] Babu, R. S., Kumar, V. S. S., Reddy, G. M., Karunamoorthy, L.: Proc. Engin., 38, 2012, p. 2956. doi:10.1016/j.proeng.2012.06.345

[23] Song, Y., Yang, X., Cui, L., Hou, X., Shen, Z., Xu, Y.: Mat. Des., 55, 2014, p. 9. doi:10.1016/j.matdes.2013.09.062

[24] Dinaharana, I., Kalaiselvan, K., Vijay, S. J., Raja, P.: Arch. Civil. Mech. Eng., 12, 2012, p. 446. doi:10.1016/j.acme.2012.08.002 
[25] Ceschini, L., Boromei, I., Minak, G., Morri, A., Tarterini, F.: Comp. Sci. Techn., 67, 2007, p. 605. doi:10.1016/j.compscitech.2006.07.029

[26] Feng, A. H., Xiao, B. L., Ma, Z. Y.: Comput. Sci. Techn., 68, 2008, p. 2141.

doi:10.1016/j.compscitech.2008.03.010

[27] Wan, L., Huang, Y., Lv, Z., Lv, S., Feng, J.: Mat. Des., 55, 2014, p. 197. doi:10.1016/j.matdes.2013.09.073

[28] Krishnan, K. N.: Mater. Sci. Eng. A, 327, 2002, p. 246. doi:10.1016/S0921-5093(01)01474-5

[29] Koilraj, M., Sundareswaran, V., Vijayan, S., Rao, R. S. K.: Mat. Des., 42. 2012, p. 1. doi:10.1016/j.matdes.2012.02.016

[30] Mahabunphachai, S., Koc, M.: Mat. Des., 31, 2010, p. 2422. doi:10.1016/j.matdes.2009.11.053

[31] Kumbhar, N. T., Sahoo, S. K., Samajdar, I., Dey, G. K., Bhanumurthy, K.: Mat. Des., 32, 2011, p. 1657. doi:10.1016/i.matdes.2010.10.010
[32] Hu, Z. L., Wang, X. S., Pang, Q., Huang, F., Qin, X. P., Hua, L.: Mat. Charact., 99, 2015, p. 180. doi:10.1016/j.matchar.2014.11.015

[33] Mishra, R. S., De, P. S., Kumar, N.: Friction Stir Welding and Processing. Cham, Springer International Publishing 2014.

[34] Larsson, H., Karlsson, L., Stoltz, S., Bergqvist, E. L.: In: Proceedings of the 2nd International Symposium on Friction Stir Welding. Cambridge, The Welding Institute TWI 2000, p. 1.

[35] Lederich, R. J., Baumann, J. A., Oelgoetz, P. A.: Friction Stir Welding and Processing. Warrendale, TMS 2001.

[36] Lee, W. B., Yeon, Y. M., Jung, S. B.: Scripta Mater., 49, 2003, p. 423. doi:10.1016/S1359-6462(03)00301-4

[37] Khodir, S. A., Shibayanagi, T., Naka, M.: Mat Trans., 47, 2006, p. 1560. doi:10.2320/matertrans.47.1560 